MIDAS

Museus e estudos interdisciplinares

2 | 2013

Varia

\title{
A inclusão social tem influência nas práticas museais? O acesso dos públicos com deficiência
}

Does social inclusion have an impact on the museum practice? Access for people with disabilities

\section{Patricia Roque Martins}

\section{OpenEdition}

\section{Journals}

\section{Edição electrónica}

URL: http://journals.openedition.org/midas/246

DOI: $10.4000 /$ midas.246

ISSN: 2182-9543

Editora:

Alice Semedo, Paulo Simões Rodrigues, Pedro Casaleiro, Raquel Henriques da Silva, Ana Carvalho

\section{Refêrencia eletrónica}

Patricia Roque Martins, « A inclusão social tem influência nas práticas museais? 0 acesso dos públicos com deficiência », MIDAS [Online], 2 | 2013, posto online no dia 16 abril 2013, consultado no dia 01 maio 2019. URL : http://journals.openedition.org/midas/246 ; DOI : 10.4000/midas.246

Este documento foi criado de forma automática no dia 1 Maio 2019.

\section{c) (1)(2)}

Midas is licensed under a Creative Commons Attribution-NonCommercial-ShareAlike 3.0 International License 


\section{A inclusão social tem influência nas práticas museais? $\mathrm{O}$ acesso dos públicos com deficiência}

Does social inclusion have an impact on the museum practice? Access for people with disabilities

Patricia Roque Martins

\section{0 modelo social da deficiência}

1 O modelo social da deficiência tem sido considerado, desde a sua criação na segunda metade dos anos oitenta, um forte instrumento conceptual para o avanço dos direitos das pessoas com deficiência. No entanto, foi a partir dos anos 90 que se tornou mais sólido, e desde o início do século XXI, que se verifica a tendência para continuar a proliferação deste movimento, fazendo parte de um dos temas da atualidade. Teve como ponto de partida o modelo médico da deficiência, com base nas práticas integracionistas desenvolvidas durante os anos sessenta e setenta. Com efeito, o desenvolvimento deste modelo social da deficiência acabou por confirmar a inoperacionalidade do modelo precedente, ou seja, o modelo médico da deficiência.

2 No que se refere aos museus, a influência do modelo social da deficiência tem-se traduzido numa clara oportunidade para serem alteradas as práticas tradicionais que caracterizam o modo habitual de se receberem os públicos com deficiência. Sob o ponto de vista social, não há dúvidas que, ao longo dos tempos, o significado da deficiência tem oscilado no modo como se traduziu no conjunto dos valores coletivos. Desde sempre, foi do senso comum, a criação de uma imagem ligada à pessoa com deficiência que tanto poderia ir desde a personificação de um pecado como a de um super-heróis que triunfava perante a "tragédia" da sua situação de incapacidade. Ao longo da sua obra, "The changing status of the blind: from separation to integration", Lowenfeld (1975) considerou que a humanidade perspetivou a deficiência de quatro formas diferentes, de 
acordo com os distintos períodos na história da inserção social da pessoa deficiente, nomeadamente, a separação, a proteção, a emancipação e a integração. Atualmente assiste-se ao desenvolvimento de um quinto período, isto é, o período da inclusão.

3 No século XX, desenvolveu-se o período de integração, no seguimento de diversos acontecimentos ocorridos durante este século, nomeadamente: a I Guerra Mundial (1914-1918) e II Guerra Mundial (1939-1945) ao causar um elevado número de pessoas com deficiência socialmente integradas. Foi sobretudo nas décadas de sessenta e setenta que as práticas integracionistas registaram maiores avanços. Como característica base apoiavam-se no modelo médico da deficiência. Este modelo médico da deficiência, desenvolvido por pessoas sem deficiência, centrou-se no paradigma do deficit e no seu tratamento, considerando a pessoa com deficiência como sendo doente, incapaz de trabalhar e de exercer as tarefas comuns sem depender de ajuda. Considerou a deficiência como um problema singular do indivíduo, responsabilizando-o por se adaptar, habilitar, ou reabilitar de modo a satisfazer e a realizar as tarefas estabelecidas pela sociedade em termos profissionais e sociais. Naturalmente que significou a imposição de um esforço unilateral, praticado apenas por pessoas com deficiência e, eventualmente com o auxílio dos seus familiares ou com o apoio institucional.

Como resultado, durante todo este período, a sociedade permaneceu alheia, a todo o processo que caracterizou a integração, não lhe sendo exigida qualquer forma de esforço na alteração das práticas sociais, atitudinais, nos espaços físicos ou na instrumentalização técnica. Acabou por não se centrar no seu essencial, ou seja, na pessoa com deficiência, pelo contrário, deu lugar à exclusão, ao esperar de si a adaptação em ambientes "normalizados", que no fundo, solicitavam a sua mudança enquanto pessoa que procurava participar na sociedade, nomeadamente, através o seu desenvolvimento social, educacional e profissional, refletindo-se inoperante no acolhimento e na aceitação das diferenças individuais.

5 No entanto, foi a partir da prática integracionista que brotou progressivamente o período da inclusão, conferindo um novo sentido ao desempenho social da pessoa com deficiência. Desenvolvido, essencialmente a partir dos anos oitenta do século XX (principalmente nos EUA e no Reino Unido), a inclusão tendeu a substituir progressivamente a integração, sendo reconhecida até aos dias de hoje. Na verdade, desde o início do século XXI que se verifica a tendência para continuar a proliferação deste movimento, fazendo parte de um dos temas da atualidade nos diversos países desenvolvidos e em vias de desenvolvimento.

6 Em oposição à integração, a inclusão tem como característica base o modelo social da deficiência, elaborado essencialmente por pessoas com deficiência. Neste caso, é a sociedade que é responsabilizada por não permitir o desenvolvimento pleno das capacidades das pessoas com deficiência e, por isso, tem o dever de sofrer alterações, nomeadamente, através da eliminação de barreiras arquitetónicas, comunicacionais e atitudinais.

Como resultado e, na tentativa de implementação prática do modelo inclusivo, foi a partir dos anos noventa, mas sobretudo no início do século $\mathrm{XX}$, que se assistiu ao desenvolvimento de políticas europeias, que não só refletiram o modo como o pensamento sobre a pessoa com deficiência tem evoluído, como também, permitiram perceber os esforços aplicados a favor da inclusão, ao desafiarem o modelo médico da deficiência, defendendo que não são as condições físicas e mentais que incapacitam, mas antes as barreiras sociais, físicas e ao nível das atitudes que previnem a participação igualitária na vida da comunidade. 
8 Em 2001, a Organização Mundial de Saúde (OMS) elabora uma nova classificação de deficiência através da Classificação Internacional de Funcionalidade, Incapacidade e Saúde (CIF) ${ }^{1}$ que, contrariamente ao documento classificativo anterior Classificação Internacional de Deficiências Incapacidades e Desvantagens de 1980, aborda não apenas as funções do corpo e as definições relacionadas com a deficiência, mas também questões relacionadas com a atividade e participação das pessoas com deficiência na comunidade, na vida social e cívica. No seu todo, reconhece que quando há facilidades no ambiente, a incapacidade é reduzida, e quando o ambiente é dificultado, a incapacidade é agravada (Barnes e Mercer 2005, 2).

De referência incontornável, é a Declaração de Madrid intitulada "Não discriminação mais ação positiva igual a inclusão social", elaborada no Congresso Europeu sobre Deficiência, em 2002, que reconhece que a lei não é suficiente para alterar as atitudes em torno da pessoa com deficiência, mas sim a ação de toda a população, e reconhece o envolvimento dos representantes e associações de pessoas com deficiência e dos representantes locais (entre os quais museus) como fundamentais ao processo da inclusão e no combate às práticas discriminatórias.

10 Também em 2003, a União Europeia proclama o "Ano Europeu das Pessoas com Deficiência" (Europa Sínteses da Legislação da União europeia 2003) com o objetivo claro de aumentar a sensibilização para a questão da deficiência em geral e em particular para as barreiras ambientais, sociais, económicas, processuais e atitudinais enfrentadas pelas pessoas com deficiência e, ao mesmo tempo, expressa um compromisso na remoção das "barreiras ambientais na sociedade que impedem a participação plena das pessoas com deficiência na sociedade".

11 Entre 2004/2010 é desenvolvido Plano de Ação Europeu - "Igualdade de oportunidades para as pessoas com deficiência". Neste caso, importa sublinhar a responsabilização não só do setor político mas também da população para os bons resultados do Plano de Ação Europeu, pois nos objetivos gerais constata-se que " $[\mathrm{t}]$ oda e qualquer legislação, por mais cuidadosamente elaborada que seja, não passará de letra-morta se não for traduzida em ações de longo prazo por uma vontade política e se não for amplamente apoiada pela população" (Comissão Europeia 2004/2010).

12 Sob esta influência europeia, Portugal reforçou a proclamação e a reformulação de algumas leis, sobretudo a partir do início do século XXI. Em 2004, a Lei n.o 38/2004 de 18 de agosto - "Regime Jurídico da Prevenção, Habilitação, Reabilitação e Participação da Pessoa com Deficiência", que revogou a lei n.․ 9/89 de 2 de maio - "Lei de bases da Prevenção, Reabilitação, e Integração das Pessoas Portadoras de Deficiência”, cuja noção de pessoa com deficiência (art. 2.ํ da Lei n.․ 38/2004, de 18 de agosto) é associada aos fatores do meio. Entre outros, refere o Princípio da Singularidade (art. $4^{\circ}$ ) que tem em consideração as circunstâncias pessoais de cada pessoa com deficiência, considerando que “[a]s pessoas com deficiência não constituem grupos homogéneos, pelo que exigem a definição de respostas específicas que vão ao encontro das suas necessidades diferenciadas e identificáveis".

13 No contexto dos museus a Lei Quadro dos Museus Portugueses, de 2004, (Lei n.․ 47/2004 de 19 de agosto), definiu o conceito de museu nos termos de “(...) facultar o acesso regular ao público e fomentar a democratização da cultura, a promoção da pessoa e o desenvolvimento da sociedade" (art. 3.ํ). No âmbito do setor educativo refere o dever do museu exercer "(...) atividades educativas que permitam o acesso aos bens culturais(...)" 
"articulados com as politicas públicas de apoio às pessoas com deficiência (...) e de combate à exclusão social (art. 42. ${ }^{\circ}$ ), e na seç̧ão relativa ao acesso público, o apoio às pessoas com deficiência, nomeadamente "(...) o direito a um apoio especifico, e a promoção de condições de igualdade na fruição cultural” (art. 59.).

De acordo com este panorama, facilmente se considera que o início do século XXI foi significante para as pessoas com deficiência da União Europeia. No entanto, e finalizada a primeira década, torna-se oportuno indagar o que mudou em Portugal em termos de ação em relação à população com deficiência para além das alterações legais que se registaram? Se por um lado, se registou a proclamação de normas e de alterações legais que brotaram de um contexto europeu, em termos práticos, a realidade nacional ainda se reporta ao período integracionista, demonstrando que o modelo social continua a ser interpretado como muitas diferenças pelos Estados-Membros, que acompanham esta questão com iniciativas específicas, no que concerne às políticas em torno da deficiência (Barnes e Mercer 2005, 26).

\section{Conceito de acessibilidades em museus no âmbito da deficiência}

15 Ao se abordar a deficiência segundo o modelo social, naturalmente que a definição de acessibilidade irá sofrer impactos, já que o modelo social remete para a experiência contextual da deficiência, que ocorre pela interseção do indivíduo com o meio, incluindo o ambiente físico, informativo e comunicacional. Consequentemente, terão que ser tidas em conta outras barreiras para além das físicas, como as intelectuais, emocionais, culturais ou financeiras. A projeção da acessibilidade no ambiente do museu dependerá, então, desta nova abordagem.

Por outro lado, as reformulações legais, aqui referidas, surgidas em Portugal ao longo da primeira década do século XXI, fruto das políticas europeias, poderão apontar para uma nova definição nas políticas museais nacionais: o primado da pessoa. Desta forma, reforçam o impacto que os museus podem ter do ponto de vista social, através da abolição das barreiras sociais. É nesta medida que o modelo social da deficiência poderá provocar alterações nas práticas museais tradicionalmente estabelecidas, isto é, a aplicação de uma verdadeira política institucional virada para a inclusão, assente num processo global dos vários setores de cada museu, e não apenas do setor educativo como tem acontecido na generalidade.

No fundo, o modelo social da inclusão acabou por reforçar a existência de um mau entendimento em relação à palavra "acessibilidade" tendencialmente interpretada ao nível nacional, apenas no sentido do acesso físico, subordinando-a aos aspetos da deficiência motora, como a existência de elevadores ou de rampas que permitem a entrada de visitantes com essa necessidade. Porém, são esquecidos os aspetos que possibilitam o acesso físico de pessoas com outras deficiências, como a visual, que implica o acesso de cães - guia ou a colocação de guias no pavimento, verificando-se que, raramente são criados meios diferenciados de acesso ao museu de acordo com as características de cada deficiência. Ainda é frequente a assunção de uma certa homogeneidade no tratamento de públicos com deficiência, como se cada género de deficiência não implicasse o cumprimento de necessidades específicas e diferenciadas. 

recreativos e de atividades que oferecem a possibilidade das pessoas com deficiência participar ativamente nelas, envolvendo o desenvolvimento de suportes e serviços necessários para esse fim, como pressupõem as práticas europeias centradas nas políticas de inclusão. Consequentemente, estas políticas de inclusão irão gerar alterações ao conceito de acessibilidades.

19 Esta definição do conceito de acessibilidades irá levar necessariamente à criação de novas relações entre museus e públicos, nomeadamente, a assunção de diferentes formas de aproximação que requerem o exercício de novas práticas museais para responder aos desafios colocados pelo modelo inclusivo.

O novo modelo que aqui se apresenta pretende agrupar três conceitos fundamentais no âmbito das acessibilidades, enunciando também as barreiras afetas ao museu no que concerne à receção de públicos com deficiência.

Fig. 1. Conceito de Acessibilidades em Museus

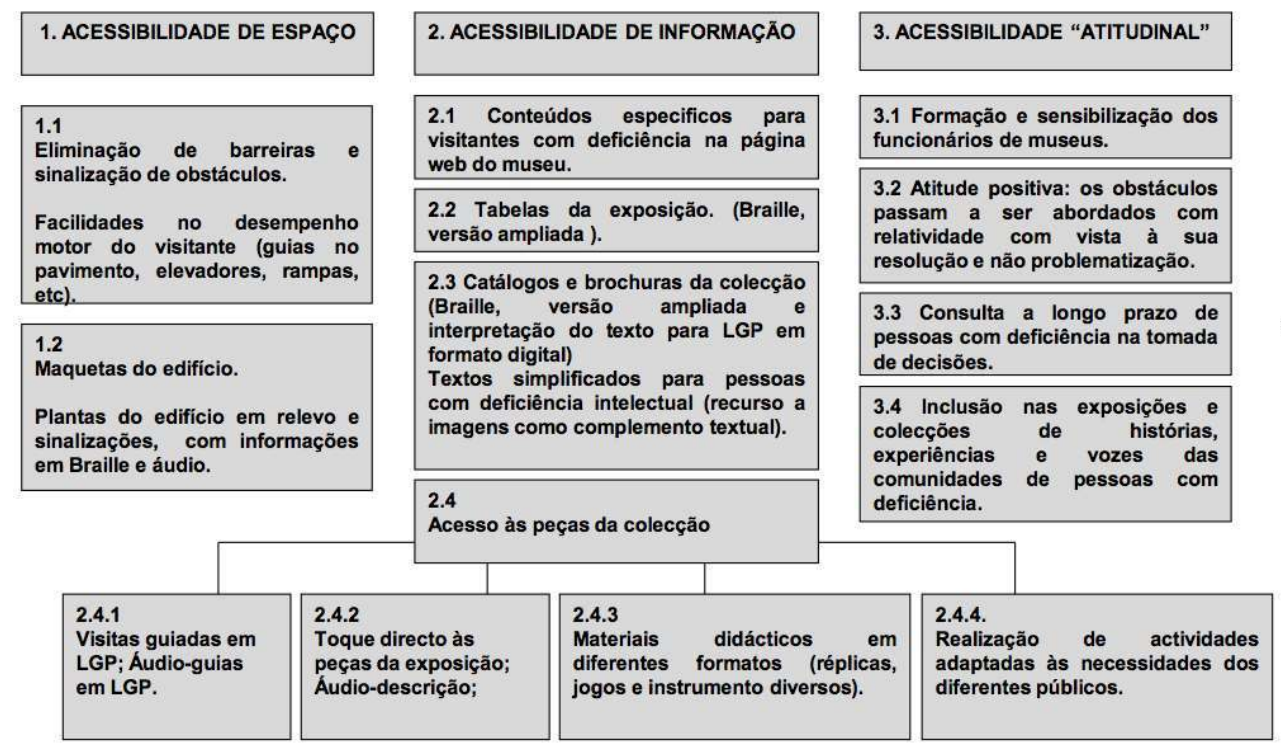

21 A acessibilidade do espaço traduz-se nas facilidades de acesso criadas em determinados ambientes que permitem não só a entrada num edifício mas a utilização dos seus serviços sem qualquer género de impedimentos. O recurso a esta expressão tem sido frequentemente associado às pessoas que usam cadeiras de rodas ou pessoas que tem outras dificuldades ao nível do desempenho motor como é o caso do público sénior. No entanto, no caso das pessoas com deficiência ao nível sensorial, o acesso físico envolve outras questões que vão para além das soluções que estas propõem. Consequentemente, não deve ser uma expressão usada em termos demasiadamente genéricos pois as soluções relativas ao acesso físico são variáveis, conforme o tipo de deficiência em apreço. Por conseguinte, terão de ser considerados meios diferenciados de acesso ao museu de acordo com as características e as necessidades específicas de cada deficiência. Desta forma, poderão ser alcançados resultados mais positivos.

Efetivamente, em termos gerais, as necessidades de acesso de uma pessoa deficiente motora não são as mesmas que as de uma pessoa com deficiência visual. Por exemplo, a colocação de guias em escadas ou em torno de obstáculos pode facilitar a acessibilidade 
física das pessoas cegas ou com baixa-visão. Já a colocação de um elevador poderá resolver questões dos acessos apenas para pessoas com deficiência motora. E tornar um edifício acessível a uma pessoa com deficiência motora implicará medidas mais profundas ao nível da arquitetura, o que se traduz num maior impacto ao nível dos recursos financeiros como a colocação de rampas, elevadores ou o alargamento de portas.

Em Portugal, algumas reformulações legislativas alertaram para esta questão da promoção do acesso físico, como o Decreto Lei n.. 123/97 de 22 de maio de 1997, que tornou obrigatória “(...) a adoção de um conjunto de normas técnicas básicas de eliminação das barreiras arquitetónicas em edifícios públicos, equipamentos coletivos e via pública para melhoria da acessibilidade das pessoas com mobilidade condicionada (... )”. Em 1999, o Decreto - Lei n. ${ }^{\circ}$ 118/99 de 14 abril estabeleceu: “(...) o direito de acessibilidade dos deficientes visuais acompanhados de cães-guia a locais, transportes e estabelecimentos de acesso público, e, bem assim, as condições a que estão sujeitos estes animais quando no desempenho da sua missão (...)" que mais tarde foi alargado às pessoas com deficiência sensorial, mental orgânica e motora acompanhadas de cães de assistência no Decreto-Lei n. ${ }^{\circ} 74 / 2007$ de 27 de março de 2007. No entanto, em termos práticos ainda são muitos os museus que, quer por questões financeiras, quer por questões relativas à salvaguarda do património histórico edificado, ou por outras questões culturais, não garantem a entrada nos seus edifícios ou a utilização dos seus serviços, sem qualquer género de impedimentos ou desconforto. $O$ caso da deficiência visual é notório, pela inexistência acentuada de guias condutoras de um determinado percurso, com o objetivo funcional de denunciar ao visitante a presença de mudanças de direções, o início de escadas, ou zonas de avanço, ou até direcioná-lo para a entrada do museu. A cor contrastante em relação ao solo, que as caracteriza, poderia ser uma solução para as pessoas com baixa visão que poderiam encontrar nestas guias pontos de referência. Exemplo desta estratégia de acessibilidade física para pessoas com deficiência visual é o Museu de Arte Moderna de São Paulo e o Museu da Bíblia, também em São Paulo, no Brasil, que colocaram guias de acesso ao museu no exterior e no interior. No entanto, a opção mais comum tem sido o recurso as maquetas e plantas do edifício que podem orientar o visitante no interior do museu, como, em certos casos, podem facilitar a compreensão das características arquitetónicas do edifício ou do seu enquadramento urbanístico.

No caso da acessibilidade de informação, é um elemento fundamental, já que se refere aos aspetos que permitem aos museus fazerem chegar corretamente a sua mensagem ao destinatário. Se essa mensagem não for suficientemente clara para ser compreendida pelo recetor, ou se for recebida de forma inadequada, vai ocorrer um bloqueio que certamente impede o diálogo entre ambos. Neste caso, o objetivo que se aplica a este modo de acessibilidades, será o de encontrar estratégias e instrumentos para um público específico, que enriqueçam e facilitem tanto a experiência como a aprendizagem dos conteúdos de uma coleção. Como tal, pressupõe uma planificação centrada nas necessidades e características de cada género de deficiência. Um catálogo em Braille centrado nos públicos com deficiência visual, de uma coleção de arte - que serve aqui de exemplo por se tratar de uma estratégia recorrente - é diferente de um catálogo em Braille adaptado de uma versão para o público geral, pela forma como descreve e explica os conceitos visuais presentes, como também, disponibiliza imagens em relevo. Desta forma, torna-se apelativo ao público a que se destina. Caso paradigmático é o da Tate Modern, em Londres, que disponibiliza através da rede web (Tate: British and 
international modern and contemporary art 2012) conteúdos específicos para pessoas cegas ou com baixa-visão, nomeadamente, descrições visuais de algumas obras selecionadas da coleção, recursos áudios para complementar as informações sobre as peças, e matrizes de desenhos para serem impressos em relevo pelos próprios utilizadores da página web (cf. http://www2.tate.org.uk/imap/).

No caso dos públicos com deficiência auditiva, uma versão em língua gestual da páginas web dos museus, poderá ser mais fácil de compreender do que uma versão em linguagem escrita. Estas dificuldades da compreensão textual devem-se ao facto da língua escrita funcionar como uma segunda língua, especialmente, quando não existem conhecimentos relativos ao significado da palavra escrita, como conteúdos mais abstratos e complexos.

Deste modo, a disponibilização de um serviço nos museus para o acesso comunicacional e informativo centrado na pessoa com deficiência auditiva, é uma forma de assegurar, não apenas um autoconceito positivo nos públicos com deficiência auditiva, mas também, o mesmo ambiente linguístico com que naturalmente se comunica e manifesta, tal como é feito com os outros públicos ouvintes, através da comunicação oral. Exemplo disso, é o caso do Bantock House Museum (2012) em West Midlands, que disponibilizou na sua página web um vídeo de apresentação do museu, desenvolvido com baixos recursos financeiros, através da plataforma do youtube (cf. http://www.youtube.com/watch?v=hYfirRjbOqs).

Outro exemplo apresenta-se através do Whitney Museum of American Art (2012), em Nova Iorque, que organiza visitas guiadas em Língua Gestual Americana realizadas por monitores surdos com formação em artes, e em simultâneo, disponibiliza a interpretação oral da visita para a língua inglesa, através do recurso a um tradutor ouvinte, permitindo que outros visitantes ouvintes presentes no museu participem igualmente nesta atividade. Nesta situação, a colocação de um monitor, com a mesma deficiência para o público a que se destina, reforça a qualidade do serviço, permitindo maiores facilidades na captação de públicos com deficiência auditiva, já que ambos se inserem na mesma comunidade.

Por último, mas não menos importante, é a acessibilidade atitudinal. Neste âmbito, a atitude reporta-se à componente afetiva refletida pelas pessoas sem deficiência perante a deficiência (Sassaki 2006, 112). Quando se refere aos museus relaciona-se com o desempenho social dos funcionários, como os rececionistas ou monitores, perante a presença de pessoas com deficiência, considerando-se que o seu desempenho social contribui amplamente para a efetivação de uma inclusão plena nos museus. Por isso, pode ou não constituir uma barreira de acesso dependendo do modo como se recebe este público. Naturalmente que se a atitude apresentada for negativa a vontade de entrar no museu ou de regressar vai certamente ser colocada em causa. Por outro lado, pode influir no grau de satisfação ou o à vontade com que é vivenciada a visita. Assim sendo, é uma vertente muito importante na projeção das acessibilidades, e que na maioria dos casos não é levada em conta, a favor dos dois géneros de acessibilidade anteriormente abordados (a informação e o acesso físico).

As atitudes negativas podem resultar da falta de informação ou da existência de preconceitos que levam as pessoas sem deficiência a sentirem-se desconfortáveis ou pouco tolerantes na presença de pessoas com deficiência. Esta é, porém, a pior barreira que pode existir, já que é a falta de sensibilidade que pode impedir, de um modo bastante direto, o bom relacionamento entre museus e públicos com deficiência. 
30 Não se pode esperar que a sociedade inclusiva aconteça de um momento para o outro. Iniciar a sua construção requer a mudança de opiniões num processo de desenvolvimento global articulado com reformulações legais e apoios financeiros. Estes dois últimos, isoladamente, não garantem a estabilidade da inclusão, sendo fundamental a dedicação e a aptidão das pessoas envolvidas. Por isso mesmo, quanto maior conhecimento as pessoas sem deficiência têm acerca das pessoas com deficiência, menos preconceituosas se tornam em relação à sua presença, e daí e importância da formação e sensibilização dos funcionários dos museus para as questões da deficiência.

31 Por outro lado, uma atitude positiva perante a inclusão pode facilmente contribuir para a superação de obstáculos, como a falta de apoios financeiros, passando a serem abordados com grande relatividade, com vista à sua resolução e não à sua problematização.

32 Nesta perspetiva, importa assinalar, a importância da criação de um coordenador especializado em acessibilidades, presente no planeamento de programas inclusivos para pessoas com deficiência, já que a falta de um funcionário cuja função no museu se direcione apenas e em exclusividade para esta área de trabalho, pode constituir uma barreira para um trabalho efetivo no âmbito das acessibilidades. Razão que pode derivar do facto, do tratamento das acessibilidades ser direcionado por um funcionário do museu com outras funções, que normalmente é centrado nas pessoas que trabalham nos serviços educativos, impedindo a execução de um trabalho contínuo e até especializado para esta área em concreto. Consequentemente, a criação de um coordenador de acessibilidades num museu, passa pela concretização de diversas funções essenciais para a programação inclusiva. Como exemplo temos a mediação de contactos sistemática e direta (que inclui as pessoas com deficiência, as organizações que trabalham no âmbito da deficiência, as famílias, as instituições educativas).

33 Noutro caso temos, a sistematização de recursos e de materiais essenciais à receção dos públicos com deficiência como a: elaboração dos materiais; a contratação de empresas para o efeito de uma forma mais consciente e responsável, possibilitando até a constituição de parcerias para o efeito, como as universidades ou instituições ligadas à deficiência; a obtenção de verbas que permitam um maior investimentos em materiais, que pode não acontecer pela falta de uma pessoa que organize todo este processo. Por último, este coordenador de acessibilidades pode acompanhar e avaliar de todo o processo implicado na inclusão, pois só assim, poderão ser repensadas algumas estratégias que não funcionem de modo a garantir a qualidade do serviço. Por outro lado, a presença de um coordenador em acessibilidade, irá facilitar o nível da consciência e de informação sobre o acesso de pessoas com deficiência em museus dentro do próprio museu - como os diretores, muitas vezes alheios a todas estas questões, monitores, os seguranças e outros funcionários que estão implicados no processo de uma visita ao museu. E também, esse nível de consciência e de informação pode, ainda, ser aplicado fora da instituição museal, através da participação em grupos de estudos, debates ou conferências e, na organização de ações de formação para pessoas ou entidades interessadas em especializarem-se neste tema, ao representar pontos de vista ou metodologias de trabalho - para que se criem pontes com o objetivo de melhorar a qualidade de vida das pessoa com deficiência.

34 A acessibilidade atitudinal passa, também, pela consulta a longo prazo das pessoas com deficiência na tomada de decisões relativas à deficiência, já que, geralmente, quando ocorre é a curto prazo acabando, por não se ir ao encontro das necessidades das pessoas com deficiência. 

experiências e vozes das comunidades de pessoas com deficiência, pode sensibilizar as pessoas sem deficiência para as questões da deficiência, e consequentemente contribuir para a mudança social.

Alguns casos nacionais servem de exemplo, e que de certa forma, contribuem para um retrocesso na sub-representação de uma cultura ligada à deficiência, tradicionalmente presente em Portugal. O trabalho fotográfico de Marcus Garcia Moreira denominado "Vida Todos os Dias", realizado num âmbito do projeto o "Intreg'arte" criado pela "CerciEspinho", em 2008, com a representação de pessoas com deficiência intelectual em cenários que faziam parte do seu quotidiano. Esteve em exposição em diversos espaços culturais, como o Centro Português da Fotografia em Lisboa, o Auditório Municipal Augusto Cabrita no Barreiro e no Museu do Trabalho Michel Giacometti em Setúbal, com o objetivo de sensibilizar a população em geral para a questão da deficiência intelectual. Este caso, é um exemplo concreto de modo como se pode estabelecer a aproximação às coleções, exposições, programação e interpretação das mesmas, para influenciar a mentalidade das pessoas, travar a discriminação e, desafiar estereótipos que levam à intolerância. Nesta perspetiva, remete para uma nova direção do trabalho dos museus, na procura de novas possibilidades nas suas coleções, ao colocar em evidência, a presença de pessoas com deficiência na história, por exemplo, como criadores de arte ou representados em obras de arte, reforçando o seu direito de pertencer ao presente em oposição de uma perspetiva estreita relativa à sua existência na história.

caso, é pólo museológico Museu do Trabalho Michel Giacometti de Setúbal, que criou, juntamente com o centro de atividades ocupacionais da APPACDM ${ }^{2}$ de Setúbal, uma exposição permanente intitulada "Nós trabalhamos com as máquinas", usando o seu potencial para informar e formar as atitudes das pessoas, de uma forma positiva e não estereotipada, de que as pessoas com deficiência sempre fizeram parte da sociedade. Neste contexto, criou-se um pólo museológico, desenvolvido a partir das necessidades de um grupo de pessoas com deficiência intelectual, que trabalhavam numa oficina de fabrico de pequenos artefactos para dossiers e calendários que ia ser encerrada. 0 museu manteve aquele espaço, onde reconstituiu ao vivo os passos da cadeia de fabrico, dinamizado pelos seus trabalhadores, ou seja, as pessoas com deficiência intelectual. É um exemplo concreto de uma posição ativa no encorajamento do respeito mútuo entre diferentes comunidades.

Se se considerar que a ideia de exclusão social, quer de pessoas com deficiência quer de outros grupos em risco de exclusão, não brota de um vazio, mas antes é definida e fixada por noções de valor da nossa cultura e pelo modo como esses valores são representados nas instituições, mais facilmente é posicionado o sentido de responsabilidade dos museus para atuarem como agentes positivos de mudança social.

Por outro lado, importa também referir que, em Portugal, nos últimos anos tem-se verificado o crescimento de estudos, no âmbito da investigação em acessibilidades em museus, desenvolvidos e aplicados nas instituições museais como é o caso daqueles que foram desenvolvidos pelas autoras Clara Mineiro (2004), Josélia Neves (2010) Josélia Neves (2010) e Sónia Santos (2011). De referência nacional, surgiu, em 2004, o Grupo de Acessibilidades em Museus (GAM), composto por profissionais de museus nacionais e membros individuais, com o objetivo claro de partilha, discussão e divulgação de ideias relacionadas com a melhoria do acesso dos públicos aos museus. 

título Alison Lapper Pregnant (2005), exposta em Trafalgar Square, em Londres, entre $2005 / 2007^{3}$. O autor, que se caracteriza por explorar questões relativas à mutabilidade do ser humano e à dicotomia entre o espiritual e o físico, representou nesta obra uma mulher com nanismo, sem braços e grávida. A forma como foi representada e, o contexto em que foi exposta, remetia o espectador para uma direção muito positiva em relação à deficiência, que provavelmente num outro contexto poderia remetê-lo para uma visão mais negativa. Qual terá sido o impacto que esta obra teve perante o público que visitou aquela praça. 0 modo como estava assente numa coluna em pedra e o próprio material de aparência marmórea de cor branca, poderia direcionar o olhar do espectador para uma noção de beleza associada à deficiência, remetendo-o para um ideal de beleza criado desde a antiguidade grega através do nu feminino. Ainda acerca da personagem ali representada (que faz parte do mundo atual) Alison Lapper, com formação em artes pela Universidade de Brighton, desenvolve o seu trabalho em torno da fotografia, imagem digital e pintura para questionar e mudar as ideias acerca da beleza física humana, daquilo que é normal, sobre a deficiência e sexualidade, recorrendo a si própria enquanto objeto artístico. Ela própria diz: "enquanto pessoa com deficiência, sou considerada feia, com uma vida sexual pouco ativa, inerte, à mercê de caridade e miserável" ${ }^{4}$ (cit. por Dodd 2001, 53). Qual será o impacto de uma exposição deste cariz no âmbito da instituição museal? Poderá provocar mudanças no pensamento acerca da deficiência do público sem deficiência que a visita? Este é mais um exemplo de uma via permissível ao papel museus na sua ação para a inclusão social.

\section{BIBLIOGRAFIA}

Aznar, A. S., e D. G. Castañón. 2008. Son Ó Se Hacen, El campo del la discapacidad intelectual estudiado a través de recorridos múltiples. Buenos Aires: Novaeduc.

Barnes, Colin, e Geof Mercer. 2005. The Social Model of Disability: Europe and the Majority World. The Disability Press: Leeds.

Congresso Europeu Sobre Deficiência. 2002. Declaração de Madrid: Não discriminação mais acção positiva igual a inclusão social. Madrid.

Carvalho, P. V. 2009. “A Primeira Escola de Surdos no Mundo (INJS)". Surdos Notícias, 1. Federação Portuguesa de Surdos: Lisboa.

Diderot, Denis. 2007. Carta sobre os cegos para uso daqueles que vêem. Nova Vega: Lisboa.

Dodd, Jocelyn, e Richard Sandell, ed. 2001. Including Museums: Perspectives on Museums, Galleries and Social Inclusion. RCMG: Leicester.

Dodd, Jocelyn, Richard Sandell, e Rosemarie Garland-Thomson, ed. 2010. Re-Presenting Disability: Activism and Agency in Museums. Routledge: London.

Mineiro, Clara, coord. 2004. Museus e Acessibilidade: Temas de Museologia. Lisboa: Instituto Português de Museus (IPM).

MIDAS, 2 | 2013 
Lerparaver. 2005. Ano europeu das pessoas com deficiência - Balanço parcial, referido a 13/09/2003. http://www.lerparaver.com/lpv/ano-europeu-pessoas-deficiencia-balanco-parcial-referido (consultado em 12 abril, 2007).

Lowenfeld, Berthold. 1975. The changing status of the blind: from separation to integration. Charles C. Thomas: Springfield.

Martins, Patrícia Roque. 2008. “A Inclusão pela Arte: Museus e Públicos com Deficiência Visual”. Dissertação de mestrado, Universidade de Lisboa.

Neves, Josélia. 2010. “Comunicação multissensorial em contexto museológico”. In Actas do I ${ }^{o}$ Seminário de Investigação em Museologia dos Países de Língua Portuguesa e Espanhola, coord. Alice Semedo e Elisa Noronha Nascimento. Vol. 2, 180-192. Porto: Faculdade de Letras da Universidade do Porto.

Organização Mundial da Saúde. 2004. Classificação Internacional de Funcionalidade, Incapacidade e Saúde, Direcção Geral da Saúde: Lisboa.

Comissão Europeia. 2004/2010. Plano de Acção Europeu Igualdade de Oportunidades para as Pessoas com Deficiência. http://europa.eu/legislation_summaries/employment_and_social_policy/ disability_and_old_age/c11414_pt.htm (consultado em julho 30, 2010).

Quinn, Marc. 2005. Alison Lapper Pregnant. http://www.marcquinn.com/work/view/year/2005/ \#/3148 (consultado em março 23, 2012).

Sandell, Richard, ed. 2002. Museums, society, inequality. London: Routledge.

Santos, Sónia. 2011. Museus inclusivos: realidade ou utopia. In Ensaios e práticas em museologia, ed. Alice Semedo e Patricia Costa, 306 - 325. Porto: Universidade do Porto. http://ler.letras.up.pt/ uploads/ficheiros/8945.pdf (consultado em outubro 17, 2012).

Sassaki, Romeu. 2006. Inclusão, Construindo uma sociedade para todos. WVA: Rio de Janeiro.

Sínteses da Legislação da União Europeia. 2003. Ano Europeu das Pessoas com Deficiência 2003. http://europa.eu/legislation_summaries/employment_and_social_policy/ disability_and_old_age/c11413_pt.htm (consultado em junho 6, 2007).

Smith, Ralph W., David R. Austin, e Dan W. Kennedy, ed. 2001. Inclusive and Special RecreationOportunities for persons with disabilities. McGraw-Hill: New York.

Tate: British and international modern and contemporary art. 2012. I-map creative access. http://www2.tate.org.uk/imap/ (consultado em março 12, 2012).

Whitney Museum of American Art. 2012. Information for visitors who are deaf. http://whitney.org/ Education/Access/DeafServices (consultado em março 12, 2012).

Wolverhampton Arts Museum. 2012. An introduction to Bantock House BSL. http:// www.wolverhamptonart.org.uk/bantock/the_house/bsl (consultado em março 12, 2012).

\section{ANEXOS}

Legislação Consultada:

Constituição da República Portuguesa. 2005. VII Revisão Constitucional atº74 alínea H. http:// www.parlamento.pt/Legislacao/Paginas/ConstituicaoRepublicaPortuguesa.aspx\#art74 (consultado em fevereiro 7, 2011) 
Decreto - lei n. 123/9. Diário da República n.ำ 118 série I-A, p. 2540-2544, de 22 de maio de 1997.

Decreto - lei n.ำ 118/99. Diário da República n.o 87 série I-A, p. 1996-1997, de 14 de abril de 1999.

Lei n. 38/2004. Diário da República n. 194 série I-A, p. 5232-5236, de 18 de agosto de 2004 .

Lei n. 47/2004. Diário da República n. 195, série I-A, p. 5379-5394, de 19 de agosto de 2004.

Lei n.ำ 46/2006. Diário da República n.ำ 165, série I, p. 6210-6213, de 28 de agosto de 2006.

Decreto - lei n.ำ 74/2007. Diário da República n. 61, série I, p. 1764-1767, de 27 de março de 2007.

\section{NOTAS}

1. O CIF (Classificação Internacional de Funcionalidade, Incapacidade e Saúde) é um documento classificativo ao nível internacional, desenvolvido pela OMS com objetivo de proporcionar uma ampla gama de informações sobre a saúde através de uma linguagem comum padronizada.

2. Associação Portuguesa de Pais e Amigos do Cidadão Deficiente Mental.

3. Imagem disponível em http://www.marcquinn.com/work/view/year/2005/\#/3148 (consultado em março 12, 2012).

4. Tradução livre.

\section{RESUMOS}

Ao longo dos últimos dez anos a agenda europeia tem colocado em evidência a inclusão social na campo das suas políticas prioritárias, através de medidas e planos de ações, que têm vindo a contribuir não só para as alterações legislativas mas também ao nível da sensibilização dos vários agentes sociais. Para responder aos desafios impostos na prática da inclusão social, são cada vez mais os museus interessados, ou preocupados, em refletir acerca das suas relações com os públicos, que no panorama museal da atualidade, exigem novas formas de abordagem. Uma delas é, sem dúvida, o conceito de acessibilidades, como resultado do modelo social da deficiência. Consequentemente, algumas questões imperam na aceção desta temática. Que desafios coloca este modelo às práticas museais tradicionalmente estabelecidas? Que transformações se processam no conceito de acesso ao museu? Quais as consequências do impacto europeu na ação dos museus nacionais? São estas questões-chave que se procurará desenvolver ao longo do presente artigo.

Over the last ten years, the European agenda has brought the field of social inclusion into its priority policies, through measures and action plans, which have contributed not only to legislative changes but also to increased levels of awareness of the different social agents. To respond to the challenges imposed by social inclusion, the number of interested, or concerned, museums is increasing, while reflecting on their relationships with the public which, in today's museum landscape, require new approaches. One is undoubtedly the concept of 
accessibility, as a result of the social model of disability. Consequently, some issues prevail. What challenges does this model pose for established traditional museum practices? What changes have taken place in the concept of access to museums? What are the consequences of the impact of EU actions on national museums? These are some key questions that will be discussed throughout this article.

\section{ÍNDICE}

Keywords: accessibility, social inclusion, social model of disability, visitors with disabilities Palavras-chave: inclusão social, modelo social da deficiência, museus e acessibilidade, públicos com deficiência

\section{AUTOR}

\section{PATRICIA ROQUE MARTINS}

Licenciada em História de Arte pela Faculdade de Letras (2001) e Mestre em "Museologia e Museografia" pela Faculdade de Belas Artes da Universidade de Lisboa (2008). Desde de 2005 que se dedica ao estudo da acessibilidade em museus, nomeadamente, com a dissertação de mestrado subordinada ao tema: A Inclusão Pela Arte - museus e públicos com deficiência visual. Atualmente, é bolseira de investigação científica da Fundação para a Ciência e Tecnologia (FCT) associada ao Centro de Investigação e de Estudos em Belas Artes (CIEBA) da Faculdade de Belas Artes da Universidade de Lisboa, onde desenvolve a tese de doutoramento intitulada: Museus Inclusivos - as artes plásticas sua fruição e prática por parte das pessoas com deficiência. patricia.roque.martins@gmail.com 